\title{
Atrioventricular conduction tissues in univentricular hearts of left ventricular type with absent right atrioventricular connection ('tricuspid atresia')
}

\author{
DAVID F. DICKINSON, JAMES L. WILKINSON, AUDREY SMITH, \\ ANTON E. BECKER, AND ROBERT H. ANDERSON ${ }^{1}$ \\ From the Department of Child Health, University of Liverpool; Royal Liverpool Children's Hospital, \\ Liverpool, and Department of Pathology, Wilhelmina Gasthuis, Amsterdam, and the Department of \\ Paediatrics, Cardiothoracic Institute, Brompton Hospital, London
}

SUMMARY The atrioventricular conduction tissues in 14 hearts with absence of the right atrioventricular connection ('tricuspid atresia') were studied by serial sectioning. In all cases, the atrioventricular node lay in the floor of the right atrium, posterior to the tendon of Todaro, but in all but one case it extended anteriorly either medial or lateral to the insertion of the tendon in a way not seen in the normal heart. The common bundle frequently arose from the anterior or lateral extensions of the node and, after penetration of the central fibrous body, came to lie on the right wall of the main ventricular chamber at the point of junction with the septum separating this chamber from the outlet chamber. In all but 3 cases, branching of the bundle occurred posterior to the outlet foramen. The distribution of the left bundle characteristically favoured the posterior part of the main chamber and the right bundle passed inferior to the outlet foramen to ramify in the trabecular zone of the outlet chamber.

Although these findings differ in some respects from those previously described in univentricular hearts with an outlet chamber and 2 atrioventricular valves, we believe that they are consistent with our view that the majority of hearts with absence of the right atrioventricular connection come within the category of the univentricular heart.

In recent years, the outlook for patients with atresia or absence of the right atrioventricular orifice has been improved by the use of corrective surgical procedures such as that developed by Fontan and Baudet (1971). During such procedures, the conducting tissue may be at risk during closure of the atrial septal defect, during closure of the outlet foramen, and when enlargement of the outlet foramen is required because the aorta arises from the outlet chamber. The disposition of conducting tissue also has implications for the morphology and classification of the anomaly.

Anderson and his colleagues (1977) have expressed the view that atresia (or absence) of the right atrioventricular orifice is, in most cases, associated with the ventricular morphology of a univentricular heart, usually with an anterior rudimentary chamber. They recognised, however, that in a small num-

${ }^{1}$ RHA is supported by the Joseph Levy Foundation together with the British Heart Foundation.

Received for publication 6 July 1978 ber of cases an imperforate tricuspid membrane interposed between the right atrium and a formed right ventricle (Anderson et al., 1977; Dickinson et al., 1979). On the other hand, Bharati et al. (1976) considered the anterior chamber in 'tricuspid atresia' to be a true right ventricle in all cases. More recently (Bharati and Lev, 1977) they have used their findings regarding the distribution of the conducting tissue in the anomaly to support this view.

We have now examined the conducting system in 14 cases of absence of the right atrioventricular orifice. Our results are here discussed with particular reference to the nomenclature of the anomaly, to the implications for surgical treatment, and to the electrocardiographic findings.

\section{Materials and methods}

The specimens studied were taken from the pathological collections of the Royal Liverpool Children's Hospital and the Wilhelmina Gasthuis, Amsterdam. After study of the morphological features and 
photography, tissue blocks were taken to include the lower part of the floor of the right atrium, the interatrial septum, the orifice of the coronary sinus, and the base of the ventricular mass including portions of the main ventricular chamber, the anterior chamber, the intervening septum, and the roots of the great arteries. The blocks were embedded in paraffin wax, sectioned at $10 \mu \mathrm{m}$ thickness and stored according to our established practice (Smith et al., 1977). Initially each fiftieth section was stained using a modification of Masson's technique. Intermediate sections were prepared and stained from areas of special interest.

Reconstructions of specimens 1 and 7 were prepared by projection of each fiftieth section onto $6 \mathrm{~mm}$ Plastazote sheets with a magnification factor of $\times 12$. The projected image was traced, cut out, and coloured to distinguish the histological features. The sheets could then be assembled in an accurate reconstruction of the original tissue block.

\section{Results}

The main morphological features of the specimens are described in Table 1. The electrocardiographic findings in 7 of the cases are presented in Table 2.

Situs solitus with laevocardia was present in all cases, with normal systemic and pulmonary venous drainage to the right and left atrium, respectively. In each specimen the right atrium was blind ending, the only outlet being via a defect in the interatrial septum (Fig. 1). This took the form of a secundum atrial septal defect in 7 cases and a widely patent foramen ovale in 6 cases. Where a dimple was present in the floor of the atrium, transillumination disclosed a potential connection only with the main ventricular chamber.

One specimen (case 7) differed from the others in that there was a cleft in the anterior leaflet of the mitral valve. The atrial septal defect extended down to the mitral annulus (Fig. 2). Examination of the ventricular septal morphology showed a small but well-defined smooth surfaced septum extending to the crux of the heart (Fig. 3A). Anteriorly this was continuous with the trabecular septum which separated the main and rudimentary chambers. The small 'inlet' septum subdivided the main chamber into a minute crevice and the major compartment which received the left atrioventricular valve and had left ventricular trabecular characteristics. The outlet chamber was in communication only with the main chamber via a small outlet foramen at the junction of the smooth 'inlet' septum with the trabecular septum (Fig. 3A). The morphology of the outlet chamber in this case was similar to that seen in the other cases and there was no communi-

Table 1 Morphological features

\begin{tabular}{|c|c|c|c|c|c|c|}
\hline Case & Situs & Dimple & Atrial septum & Outlet chamber & $\begin{array}{l}\text { Aorta from } \\
\text { outlet chamber }\end{array}$ & $\begin{array}{l}\text { Pulmonary artery } \\
\text { from outlet chamber }\end{array}$ \\
\hline 1 & $\mathbf{S}$ & + & PFO & $\mathbf{R}$ & 0 & + \\
\hline 3 & $S$ & + & Sec & $\mathbf{R}$ & 0 & + \\
\hline 4 & $\mathbf{S}$ & 0 & $\mathrm{Sec}$ & $\mathbf{R}$ & 0 & + \\
\hline 5 & S & + & PFO & $\mathbf{R}$ & 0 & + \\
\hline 6 & $S$ & 0 & PFO & $\mathbf{R}$ & 0 & + \\
\hline 8 & $\mathbf{S}$ & 0 & $\mathrm{Sec}$ & $\mathbf{R}$ & 0 & + \\
\hline 9 & $\mathbf{S}$ & + & PFO & $\mathbf{R}$ & 0 & + \\
\hline 10 & $\mathbf{S}$ & + & PFO & $\mathbf{R}$ & + & 0 \\
\hline 11 & $\mathbf{S}$ & + & $\mathrm{Sec}$ & Anterior & + & 0 \\
\hline 12 & $\mathbf{S}$ & 0 & PFO & $\mathbf{R}$ & + & 0 \\
\hline 13 & $S$ & + & $\mathrm{Sec}$ & $\mathbf{R}$ & $0^{\star}$ & + \\
\hline 14 & $\mathbf{S}$ & + & Sec & $\mathbf{R}$ & + & 0 \\
\hline
\end{tabular}

*The aorta was left sided and anterior ('anatomically corrected malposition').

+ , Present; 0, Absent; Prim, primum atrial septal defect; Sec, secundum atrial septal defect; PFO, patent foramen ovale; S, solitus.

Table 2 Electrocardiographic features

\begin{tabular}{|c|c|c|c|c|c|}
\hline Case & Rhythm & $P R$ interval & $Q R S$ axis & QRS duration & Comments \\
\hline 1 & Sinus & $0 \cdot 10$ & $-40^{\circ}$ & 0.06 & $Q$ in aVL but not in V6 \\
\hline 3 & Sinus & 0.09 & $0^{\circ}$ & 0.07 & \\
\hline 6 & Sinus & 0.08 & $-40^{\circ}$ & 0.06 & \\
\hline 7 & Sinus & $0 \cdot 11$ & $-10^{\circ}$ & 0.06 & No septal $Q$ in V6 or aVL \\
\hline 8 & Sinus & $0 \cdot 10$ & $-10^{\circ}$ & 0.08 & \\
\hline 12 & Sinus & $0 \cdot 10$ & $+60^{\circ}$ & 0.08 & No septal $Q$ in V6 or aVL \\
\hline
\end{tabular}




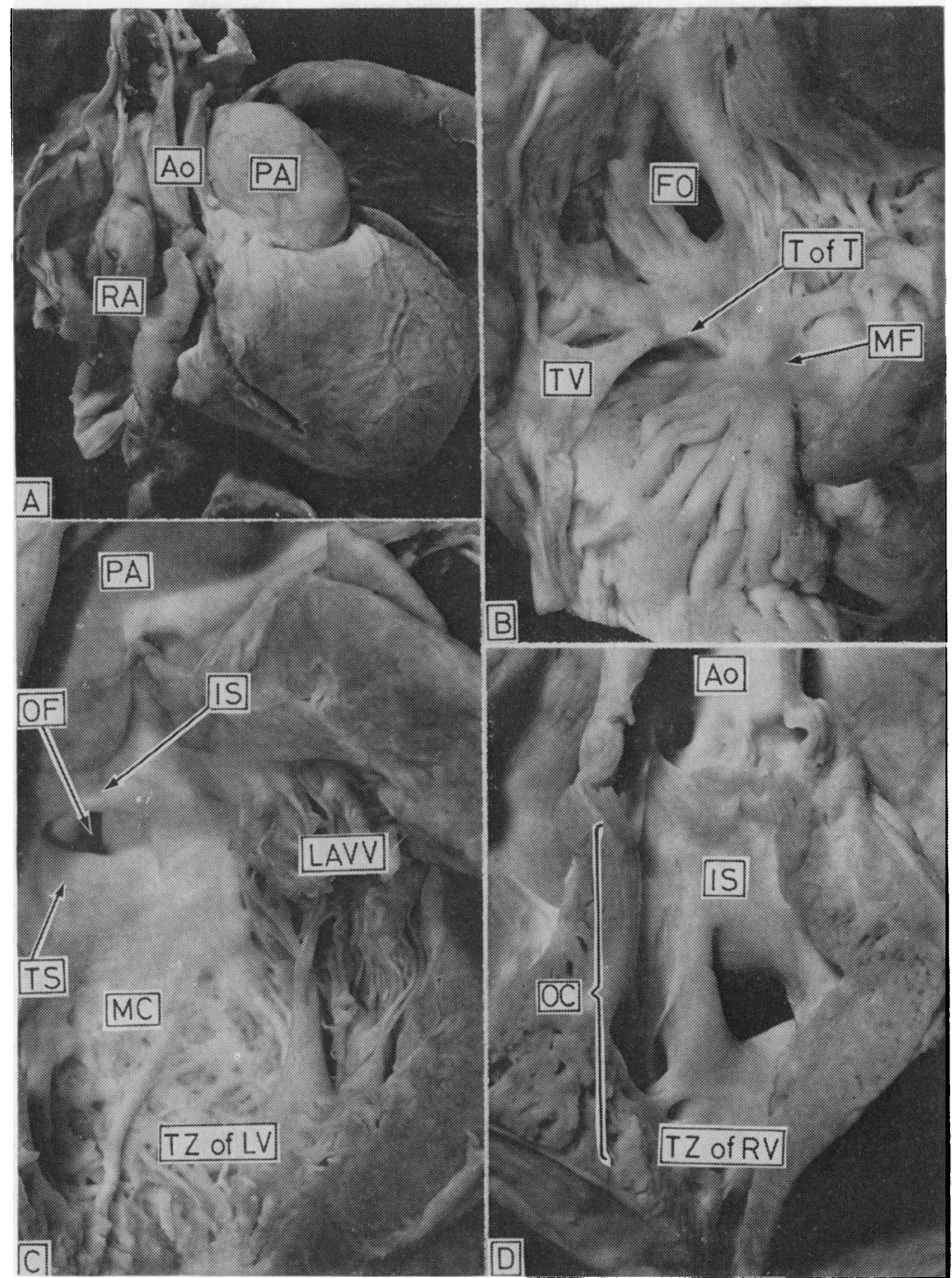

Fig. $1(A)$ The external appearance of case 14 viewed from the anterior aspect. The aorta arises from an outlet chamber on the right anterior shoulder of the ventricular mass. (B) The right atrium of case 14 . (C) The main ventricular chamber of case 14. (D) The outlet chamber of case 14.

Ao, aorta; $P A$, pulmonary artery; $R A$, right atrium; $F O$, foramen ovale; $T$ of $T$, tendon of Todaro; $M F$, muscular floor of right atrium; TV, Thebesian valve; $M C$, main chamber; OC, outlet chamber; OF, outlet foramen; $L A V V$, left atrioventricular valve; IS, infundibular septum; TS, trabecular septum; TZ of $L V$, trabecular zone of left ventricular type; $T Z$ of $R V$, trabecular zone of right ventricular type.

cation between the 'outlet chamber' and the hypoplastic crevice.

HISTOLOGY (Table 3 )

In all cases the atrioventricular node occupied a constant position in the floor of the atrium in close or intimate relation with the central fibrous body. The dimple, when present, lay anterolateral and immediately adjacent to the node. The main body of the node lay posterior to the insertion of the tendon of Todaro in all cases, but was in direct contact with the right atrioventricular sulcus (Fig. 4A). In 


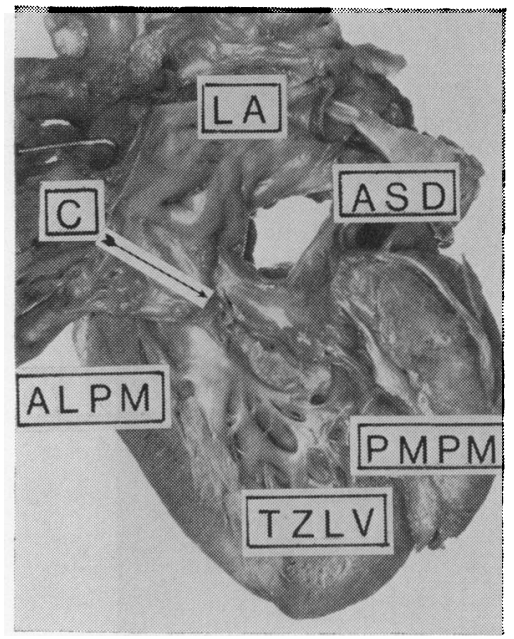

Fig. 2 The left atrium and main ventricular chamber of case 7, showing a large atrial septal defect extending to the left atrioventricular annulus. The cleft in the left atrioventricular valve is indicated. $L A$, left atrium; $C$, cleft; $A S D$, atrial septal defect; TZLV, trabecular zone of left ventricular type; PMPM, posteromedial papillary muscle; $A L P M$, anterolateral papillary muscle.

all 13 cases, the node extended anteriorly, either medial or lateral to the insertion of the tendon, and in 9 of these cases the penetrating bundle took origin from this anterior extension. In case 7 , the atrioventricular node was situated immediately adjacent to the hypoplastic posterior rim of the atrial septal defect, and the right atrium was potentially in connection with the 'crevice' previously described.

After penetration of the central fibrous body (Fig. 4C) the common bundle came to lie on the right parietal wall of the main ventricular chamber at the point of junction with the septum separating the main chamber from the outlet chamber (Fig. 4D). In this proximal position the bundle was buried within the myocardium, and only in case 7 did the bundle lie on the crest of the septum as it does in a normally septated heart.

In this case the perforating bundle lay on the crest of the septum between the main chamber and the 'crevice' previously described (Fig. 3B). The bifurcation of the bundle in this case, as in the majority of the remaining cases, lay posterior to the outlet foramen (Fig. 5). In cases 2, 4, and 13, branching of the main bundle occurred at the posteroinferior margin of the outlet foramen. A left bundle-branch was present in all cases and characteristically favoured the posterior part of the trabecular septum and the septal-parietal wall junction. In cases 7 and 12 the left bundle-branch

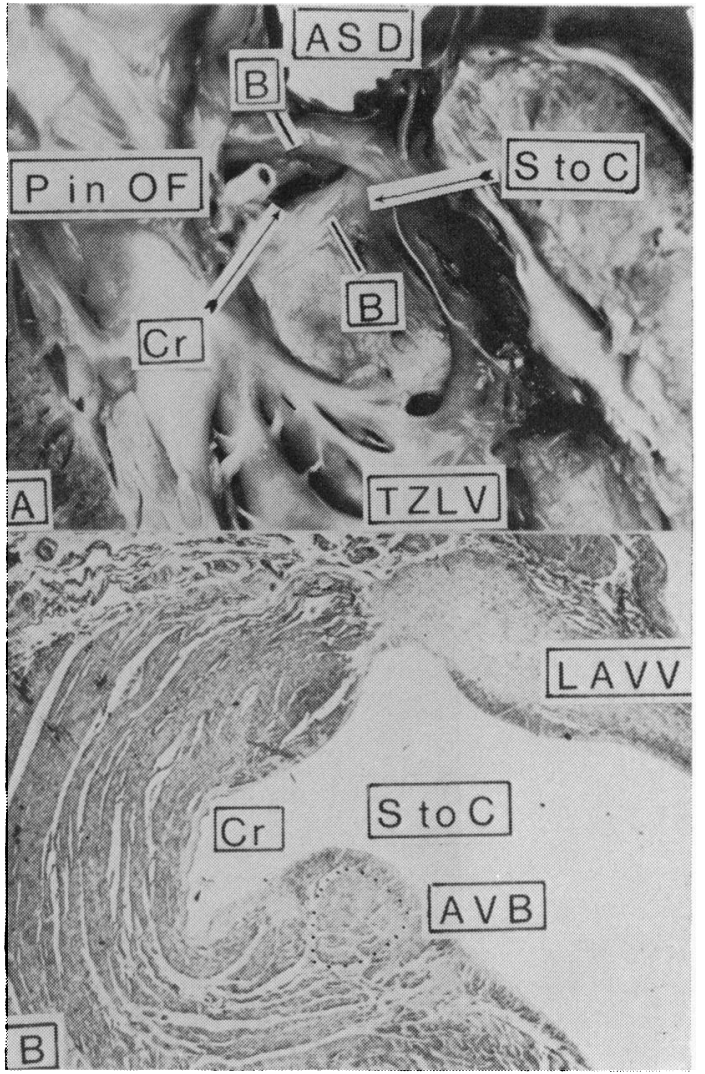

Fig. $3(A)$ The main ventricular chamber of case 7. The left atrioventricular valve has been detached from the posteromedial papillary muscle and reflected through the atrial septal defect. ASD, atrial septal defect; $P$ in $O F$, probe in outlet foramen; $C r$, crevice; $S$ to $C$, septum extending to the crux of the heart. $B-B$ plane of section in Fig. 3B. TZLV, trabecular zone of left ventricular type. (B) Photomicrograph of case 7 showing the atrioventricular bundle on the crest of the septum between the main chamber and the crevice.

$C r$, crevice; $A V B$, atrioventricular bundle; $L A V V$, left atrioventricular valve; $S$ to $C$, septum to crux of heart.

was relatively poorly developed and connection with the main bundle, though present, was tenuous. From the point of branching, the right bundle took an intramuscular course, inferior to the outlet foramen. The right bundle-branch was poorly developed in case 10 and was absent in cases 6,9 , and 13.

\section{Discussion}

Our results show an abnormal disposition of the atrioventricular conducting tissue in hearts with 'classical tricuspid atresia'. The atrioventricular 
Table 3 Histological features of conducting tissue

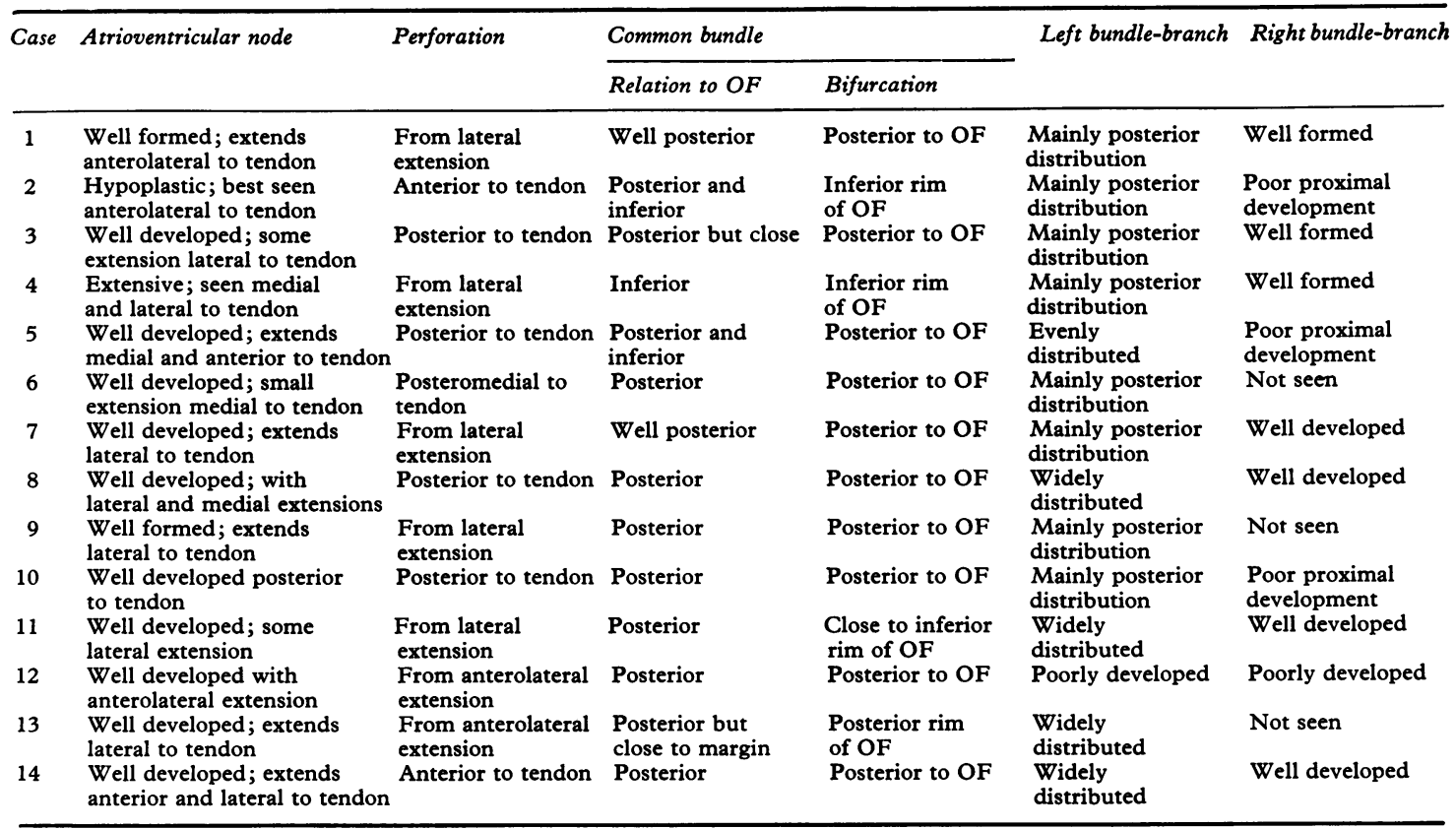

Tendon, tendon of Todaro; OF, outlet foramen.

node was closely related to the tendon of Todaro in all cases, so that from the right atrial aspect the node had a relatively normal position. However, in all cases it was related to the right atrioventricular sulcus rather than the posterior sulcus as in the normal heart (Fig. 6). Furthermore, in 13 cases the node extended anteriorly beyond the point of insertion of the tendon of Todaro into the central fibrous body. It then descended onto ventricular myocardium which constituted the parietal free wall at the site of junction with the septum separating the outlet chamber from the main ventricular chamber.

Although these observations do not differ greatly from the findings of Guller et al. (1969) and Bharati and Lev (1977), there are significant differences in interpretation. Bharati and Lev (1977) contrasted the posteriorly situated atrioventricular node seen in 'tricuspid atresia', with the anteriorly situated node and conducting pathway seen in univentricular hearts of left ventricular type with outlet chamber. They used this in support of their view that 'tricuspid atresia' is not a variant of the univentricular heart, arguing that if it were, then an anteriorly located node and conducting pathway should be anticipated. We have previously suggested (Anderson et al., 1974) that the absence of a posterior conduction pathway in double inlet univentricular hearts of left ventricular type was related to absence of a posterior inlet septum extending to the crux of the heart. When the right atrioventricular connection is absent, as in classical 'tricuspid atresia', then the inlet septum is almost invariably absent. The acute margin of the heart necessarily approximates to the crux (Fig. 6). In this situation, whatever the position of the node localised in the floor of the right atrium it will be able to make contact with conduction tissue in the anterior trabecular septum. Moreover, in the univentricular heart with a formed right atrioventricular orifice, the various areas of specialised tissue from which a conducting pathway may arise are separated by the valve orifice. If such a valve orifice is totally absent these different areas will be aggregated into a confluent zone. Thus, the anticipated anterior node of the univentricular heart of left ventricular type will be approximated to and be confluent with the anticipated site of the regular node. There is, therefore, no possibility in classical 'tricuspid atresia' of a separate anterior node and connection. In several of our specimens the penetrating bundle took origin from the anterolateral portion of the nodal aggregation, anterior to the insertion of the tendon of Todaro. This, in our opinion, is entirely compatible with the arrangement of conducting tissue seen in the univentricular heart of left ventricular type with 2 atrioventricular ostia. 


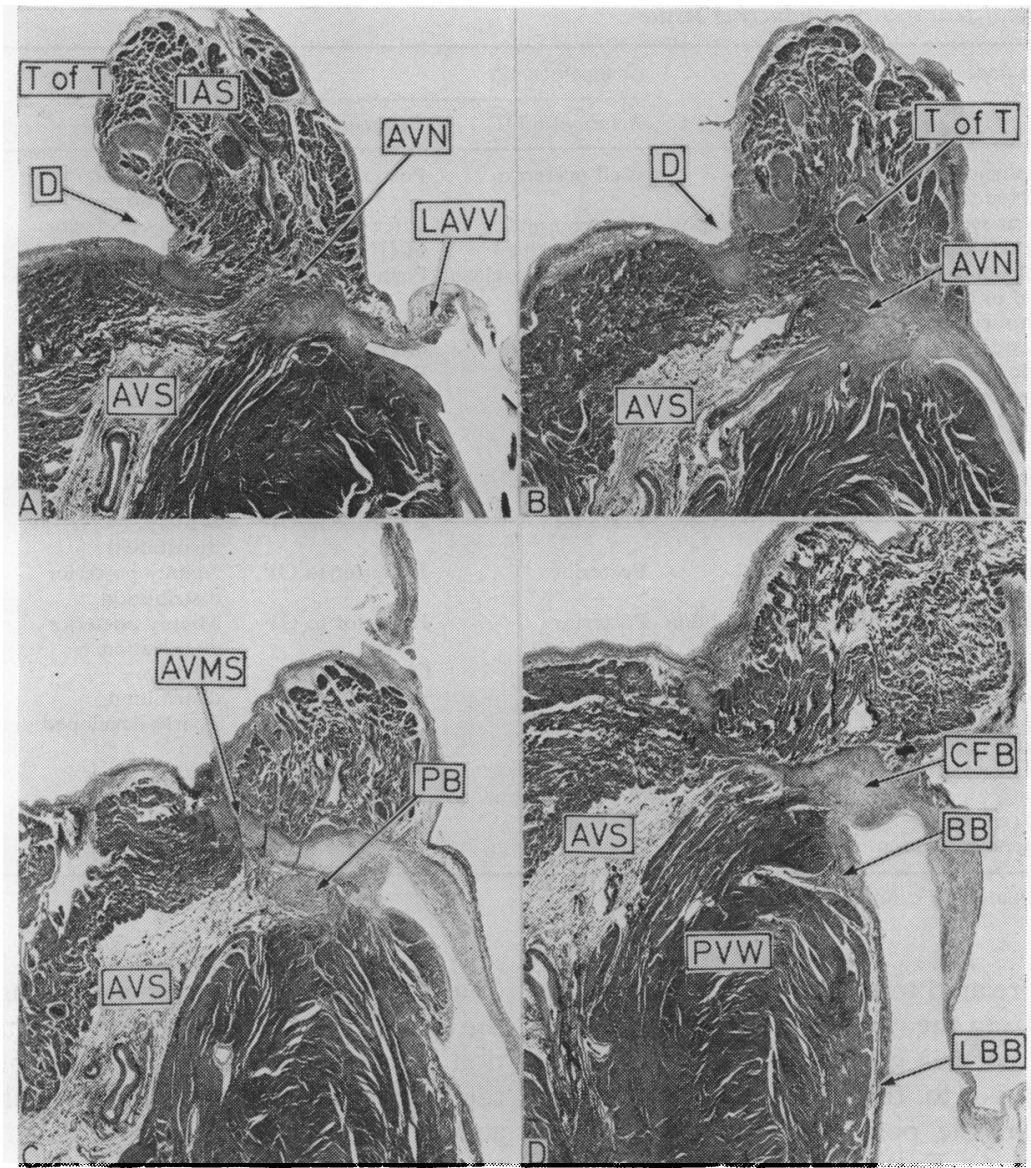

Fig. 4 The atrioventricular conducting tissue of case 14. ( $A$ ) $A$ well-formed atrioventricular node is present posterior to the insertion of the tendon of Todaro and related to the right atrioventricular sulcus. $(B)$ The tendon of Todaro is seen at the point of insertion into the central fibrous body. $A$ well-developed lateral extension to the node is present extending anteriorly to connect with the penetrating bundle. (C) The common bundle is seen after penetration of the central fibrous body. (D) The bundle now lies on the parietal ventricular wall and is seen at the point of division into left and right bundle-branches. $T$ of $T$, tendon of Todaro; $A V N$, atrioventricular node; IAS, interatrial septum; $D$, dimple in right atrium; $L A V V$, left atrioventricular valve; $A V M S$, atrioventricular membraneous septum; $P B$, penetrating bundle; $A V S$, atrioventricular sulcus; $P V W$, parietal ventricular wall; $B B$, branching bundle (at the point of origin of the right bundle-branch); $L B B$, left bundle-branch.

When we consider the distribution of conducting tissue within the ventricular mass, our findings in hearts with absent right atrioventricular connection are virtually identical with those previously reported in univentricular hearts of left ventricular type with double inlet connection (Anderson et al., 1974; Bharati and Lev, 1975). They differ considerably from hearts with atrioventricular concordance but an imperforate tricuspid membrane (Dickinson et al., 1979). In these latter specimens the conducting tissue is directly comparable with that seen in isolated ventricular septal defect (compare Fig. 5A, 6B).

Case 7 serves merely to emphasise these contentions. It possessed a hypoplastic 'inlet' septum separating a tiny crevice from the main body of the ventricular chamber. We interpreted this crevice as representing an unexpanded but discrete 'right ventricular inlet portion'. The location of the 

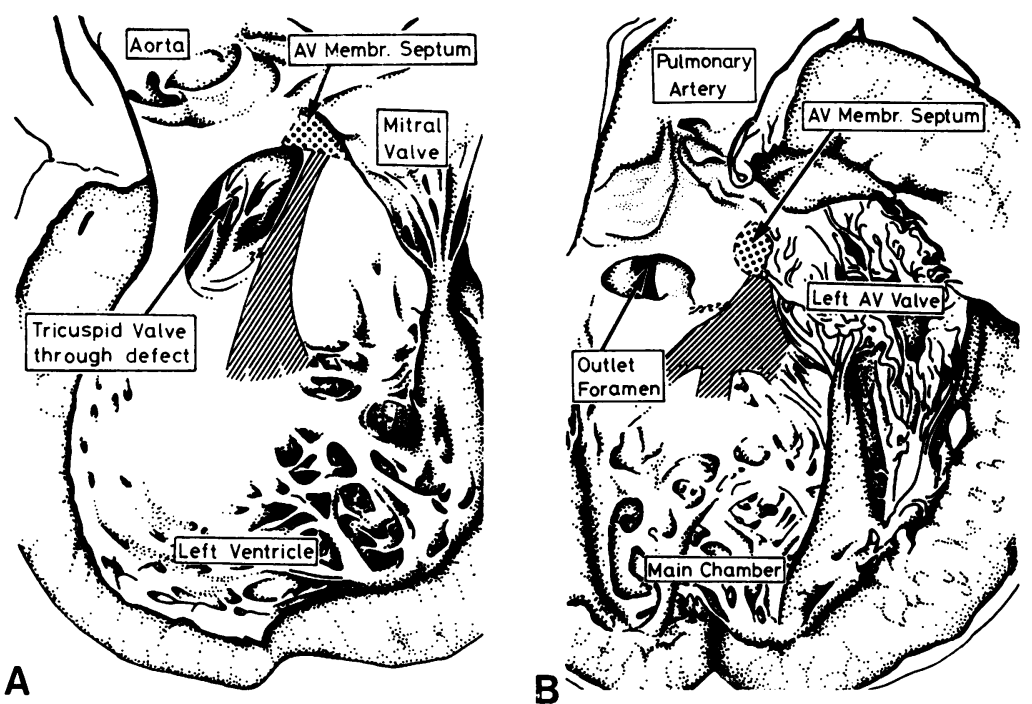

Fig. 5 (A) Diagram of the distribution of conducting tissue within the left ventricle of a heart with atrioventricular concordance and a ventricular septal defect. Note the central position of the origin of the left bundle-branch on the septum. (B) Diagram of the conducting tissue in the main ventricular chamber of a univentricular heart of left ventricular type with absence of the right atrioventricular orifice. The orientation of this diagram corresponds to the orientation of the specimen in Fig. $1 C$. Note the displacement of the left bundle-branch posteriorly relative to the septum.

Fig. 6 (A) Diagram to illustrate the relations of the atrioventricular node in the normal heart. The body of the node sits astride the inlet ventricular septum and is related at its posterior extremity to the posterior atrioventricular sulcus. The tricuspid orifice separates the acute margin of the heart (open star) from the crux (closed star). (B) Diagram to illustrate the relations of the atrioventricular node in the univentricular heart with absence of the right atrioventricular orifice. The node is related to the right atrioventricular sulcus and absence of the tricuspid valve results in approximation of the acute margin to the crux of the heart. bundle on the crest of the septum between it and the body of the main chamber confirmed this interpretation. There was no communication between the crevice and the outlet chamber, which in all respects resembled that seen in the other specimens. As would have been expected, the right atrium was in potential connection with the hypoplastic 'right ventricular inlet portion'. We submit that these findings endorse our view (Anderson et al., 1977) that the anomaly is unequivocally a univentricular heart.

\section{SURGICAL IMPLICATIONS}

The major significance to the surgeon of a detailed knowledge of the atrioventricular conduction tissues in classical 'tricuspid acresia' relates first to the position of the atrioventricular node within an atrium with abnormal geometry and secondly to the relation of the bundle and its branches to the outlet foramen. It is important, therefore, to appreciate that the atrioventricular node is in close relation to the tendon of Todaro, which is a readily identifiable landmark during surgical exposure. In addition the node lies immediately adjacent to the 'dimple', if present, in the floor of the right atrium. Where the inferior limbus of the atrial septal defect is deficient, as in case 7 , the atrioventricular node may be extremely vulnerable to damage during closure of the defect.

The penetrating bundle and its branches may be at risk during procedures that involve the outlet foramen. It should be remembered that the bundle lies on the main chamber aspect of the trabecular 
septum and usually divides posterior to the outlet foramen. Occasionally, the branching bundle may be in close proximity to the posteroinferior rim of the foramen and the right bundle-branch may lie subendocardially in the rim of the defect. From these findings it seems probable that enlargement of the outlet foramen by resection of its anterior and superior margin would be unlikely to jeopardise the conduction system. Similarly, closure of the foramen should usually be accomplished safely provided that deep sutures are not placed in the posteroinferior quadrant.

Previous authors have suggested that an abnormality of the left bundle-branch might explain some of the characteristic electrocardiographic findings in hearts with absence of the right atrioventricular orifice. An anomalous course of the left bundlebranch was suspected by Gamboa et al. (1966) and this concept was supported by the findings of Guller et al. (1969). Our findings are in keeping with those of Guller et al. (1969) and further support the concept of an abnormal distribution of the left bundle-branch. We did not observe any bundlebranch fibrosis as suggested by Puri and Neill (1966). However, in a number of our cases the bundle-branches were hypoplastic and this may have influenced the sequence of ventricular activation, particularly in case 12 .

A counterclockwise, superiorly orientated frontal plane QRS loop may result from asynchronous activation of the left ventricle. Early activation of the posterior left ventricular wall has been demonstrated in ostium primum atrial septal defect by Durrer et al. (1966) and Boineau et al. (1973). The abnormal distribution of the left bundle-branch seen in our cases of absence of the right atrioventricular orifice might similarly lead to early activation of the posterior ventricular wall. However, the typical electrocardiographic findings were also seen in 2 of the cases with atrioventricular concordance and imperforate tricuspid membrane (Dickinson et al., 1979) even though in these latter cases welldeveloped anterior and posterior radiations of the left bundle-branch were present. Our studies suggest that in any heart with absence or atresia of the right atrioventricular orifice, shortening or absence of the posterior portion of the septum may lead to the posterior displacement of the bifurcation of the bundle relative to the ventricular mass as a whole.

\section{References}

Anderson, R. H., Arnold, R., Thapar, M. K., Jones, R. S. and Hamilton, D. I. (1974). Cardiac specialised tissue in hearts with an apparently single ventricular chamber (double inlet left ventricle). American fournal of Cardiology, 33, 95-106.

Anderson, R. H., Wilkinson, J. L., Gerlis, L. M., Smith, A., and Becker, A. E. (1977). Atresia of the right atrioventricular orifice. British Heart fournal, 39, 414-428.

Bharati, S., and Lev, M. (1975). The course of the conduction system in single ventricle with inverted (L-) loop and inverted (L-) transposition. Circulation, 51, 723-730.

Bharati, S., and Lev, M. (1977). Conduction system in tricuspid atresia with and without regular (d) transposition. Circulation, 56, 423-429.

Bharati, S., McAllister, H. A., jun, Tatooles, C. J., Miller, R. A., Weinberg, M., jun, Bucheleres, G., and Lev, $M$. (1976). Anatomic variations in underdeveloped right ventricle related to tricuspid atresia and stenosis. Fournal of Thoracic and Cardiovascular Surgery, 72, 383-400.

Boineau, J. P., Moore, N. E., and Patterson, D. F. (1973). Relationship between the E.C.G. ventricular activation and the ventricular conduction system in ostium primum A.S.D. Circulation, 48, 556-564.

Dickinson, D. F., Wilkinson, J. L., Smith, A., and Anderson, R. H. (1979). Atresia of the right atrioventricular orifice with atrioventricular concordance. British Heart fournal, 42, 9-14.

Durrer, D., Roos, J. P., and Van Dam, R. Th. (1966). The genesis of the electrocardiogram of patients with ostium primum defects (ventral atrial septal defects). American Heart fournal, 71, 642-650.

Fontan, F., and Baudet, E. (1971). Surgical repair of tricuspid atresia. Thorax, 26, 240-248.

Gamboa, R., Gersony, W. M., and Nadas, A. S. (1966). The electrocardiogram in tricuspid atresia and pulmonary atresia with intact ventricular septum. Circulation, 34, 24-37.

Guller, B., DuShane, J. W., and Titus, J. L. (1969). The atrioventricular conduction system in two cases of tricuspid atresia. Circulation, 40, 217-226.

Puri, P. S., and Neill, C. A. (1966). Vectorcardiographic study in ten cases of tricuspid atresia. In Electrocardiography in Infants and Children, pp. 269-278, ed D. E. Cassels and R. F. Ziegler. Grune and Stratton, New York.

Smith, A., Ho, S. Y., and Anderson, R. H. (1977). Histological study of the cardiac conducting system as a routine procedure Medical Laboratory Sciences, 34, 223-229.

Requests for reprints to Dr James L. Wilkinson, Institute of Child Health, Alder Hey Children's Hospital, Eaton Road, Liverpool L12 2AP. 